\title{
Concept of Advanced Personal Rapid Transit at Airports
}

\author{
Kenku Mobolaji ${ }^{1}$, Dávid Földes ${ }^{1 *}$, Csaba Csiszár $^{1}$ \\ ${ }^{1}$ Department of Transport Technology and Economics, Faculty of Transportation Engineering and Vehicle Engineering, Budapest \\ University of Technology and Economics Department, Múegyetem rakpart 3, H-1111 Budapest, Hungary \\ * Corresponding author, e-mail: foldes.david@mail.bme.hu
}

Received: 21 July 2020, Accepted: 31 October 2020, Published online: 16 November 2020

\begin{abstract}
The increase in air transportation demand implies challenges on airport ground access. Using private transportation mode to reach the airport is a typical practice which results in the vast demand for parking facilities. These facilities are located farther from the terminal, increasing the access time. This research aimed to develop the concept of an advance airport Personal Rapid Transit (PRT) that connects parking facilities to the terminal as a shuttle service, and provides on-board integrated flight-related services, such as check-in and baggage handling. The system architecture and operational models were developed, thus all relevant components and functions were identified, especially focusing on information management tasks. A questionnaire survey was performed and conducted at Budapest Airport to reveal the user expectations towards an advanced PRT service at the airport. Moreover, a layout selection method was developed which was applied to Budapest Airport as a case study. The proposed PRT service provides a seamless transit by access to airport terminals from remote parking facilities conveniently and the time consumption of flight-related activities is significantly reduced too.
\end{abstract}

\section{Keywords}

airport ground access, personal rapid transit, PRT, shuttle service, system model, operational model, service integration

\section{Introduction}

Airport accessibility is a key factor that influences the airport choice of travelers [1]. It determines the perceived quality of the entire flight. The private or public mobility forms are selected by the evaluation of various factors based on user preferences. The disadvantage of private car usage is that parking at the airport is time-consuming, finding an appropriate parking space with reasonable distance from the gate can be frustrating, as well as car storage near the terminal is expensive. As air travel performance is increasing, the needed space for parking is multiplied. The large long-term parking areas are usually located far from the terminal which results in long walking distances. Nevertheless, air travelers often prefer to access the airport with private transportation because it offers a door-to-door service, more comfort, and easier baggage transfer.

Different solutions, such as shuttle bus service, have been implemented to solve connection problems relating to farther parking places from the terminal. However, these solutions could be sometimes uncomfortable due to unsatisfactory circumstances (e.g. waiting in a stop without shelter, insufficient capacity, excessive noise, emissions) and may require long waiting times (e.g. waiting for another passenger in order to achieve a sufficient passenger occupancy load).

Serving the transit demands of individual air travelers that use the parking facility in the airport does not require a high capacity transit system. That is why PRT (Personal Rapid Transit) is more compatible and was chosen for further analysis. The PRT system is a type of transit system that contains a fleet of small, mostly electric and automated vehicles capable of transporting a small number of passengers that vary from one to six [2, 3]. An advanced PRT system would revolutionize the purpose of automated transit services at airports by not just providing mobility but also delivering flight-related services to passengers while onboard a PRT vehicle. These services are security screening, baggage processing, check-in, and ticketing. Inthis research, our main aim was to develop the system concept of the advanced airport PRT. Moreover, further aims were to reveal the general expectations of air passengers towards an advanced airport PRT service and elaborate a layout selection method. 
This paper is structured as follows: Section 2 reviews the relevant literature. Section 3 summarizes the concept of the advanced PRT; the system model and the functional model have been proposed to determine the main data groups and data flows of the information management processes. Furthermore, the advanced PRT is compared to other airport ground access mobility forms. Section 4 describes the questionnaire survey and the user expectations resulted from it. In Section 5, the layout selection method is introduced and demonstrated at Budapest Airport (BUD). The paper is completed by the concluding remarks.

\section{Literature review}

Accessibility is one of the key aspects for assessing a mobility service. A service is more attractive if door-todoor mobility is provided [4]. In the case of air travel, only door-to-curb travel can be considered; access and egress travels are needed. As, in normal circumstances, the volume of air traffic is continuously growing [5], the need for better ground access is necessary. A study shows if the level of airport accessibility rises by $1 \%$, the passenger traffic will increase by $2 \%$, and the competitiveness of the airport will be significantly improved [6].

Airport ground access can be classified into three categories:

- private vehicles,

- transit services and

- non-motorized modes (e.g. walking).

The reliability of airport ground access modes (such as punctuality) was found as one of the key aspects [7]. Additional influencing factors for choosing airport ground access mode are as follows: the trip distance, type of flight destination, flight ticket price, vehicle ownership, employment status, travelling group size, location of the trip origin with respect to public transit influence, and the time difference between the flight time and departure time [8]. Anderson and Sullivan [9] ascertained that the perceptions of service quality affect satisfaction which affects loyalty and post-purchase behaviors. Expectations towards a transfer service are the following: timesaving, flexible, comfortable and cost-effective. The modal share of airport ground access highly depends on the availability of good public transport connections. Usually, airport ground access by public transportation has longer travel time significantly and a smaller service are when compared with access by car [10]. However, if the speed and travel time of public transport is good, it is chosen by the travelers [11], even if they spend more money for express service [12].
Though parking spots are located farther from the terminal in general, private car use is significant. The private car is the most used as it is perceived as the one offering more comfort, convenience, personal security and reliability [13]. Furthermore, a car is chosen with a higher possibility if travelers use a car in everyday commuting [14]. At large airports, it is estimated that private cars account for $65 \%$ of ground access journeys. While this trend can be as high as $99 \%$ at smaller regional or secondary airports, that typically struggle to support regular public transportation services [15]. The aim of the European Commission is to reduce the intra-European travel chain time to four hours. For that, airport access and egress times must be reduced. Currently, the speed of public transport is the lowest. Therefore, passengers with a higher value of time, including business travelers, for example, are more likely to access the airport by car [11]. For them, the access time can be further reduced with a good shuttle service between the parking facility and terminal.

Notwithstanding the cost of damage caused by $\mathrm{CO} 2$ per trip by car usage is high, the pollution caused by car users who park at the airport is lower than that of a taxi, minibus or 'drop off and pick up' users [16]. However, it is widely accepted that car use should be decreased if the aim is to create a green and sustainable airport [17, 18]. The CO2 emissions per passenger $\mathrm{km}$ on public transport are particularly the lowest [16].

Not only the walking distance to the terminal can be high with the use of a private car, but the distance that needs to be covered inside the terminal. Although, the main objective of the airport terminal is to connect the ground access system and the aircraft [19], terminals are also developed for hospitality management (bars, restaurants, accommodation, shopping areas) in order to improve user satisfaction [20]. An airport terminal should consist of a ground access interface, a system of components for processing passengers and baggage handling, airport administration, as well as operations and maintenance. These necessary functions increase the walking distance.

Airport transit systems are dynamic because the demand and processes vary in time. Focusing on walk distance reduction at airports, an on-demand and energy-efficient shuttle transport service is to be provided. This ensures a secure and barrier-free way for the vehicles, moreover, reduces environmental impact. Currently, shuttle bus services are operating to connect remote parking facilities and the terminal (usually with fix stop points and timetable). However, an automated system is more appropriate to 
satisfy this fluctuating demand because of minimal human interaction. For instance, drivers' work regulations do not have to be considered and smaller headway can be provided by automatic acceleration, braking, and control. When comparing public transportation and private vehicles without automation, the cost of private vehicle is always lower than with public transportation modes, automated vehicles affect the competitiveness of public transit [21].

Automated transit systems vary in shape and size, operational method, source of power and type of guideway as shown in Table 1.

Automated People Mover (APM) is a type of transit system in which vehicles are automatically controlled over exclusive guideways. The monorail is a term used to describe a form of people mover whereby all vehicles run above or are suspended below a single rail or beam. Automated Light Rail Transit (ALRT) is similar to their non-automated counterparts, except that they are fully driverless and are mostly powered by overhead electrical wires. Transit systems such as the Monorail and ALRT have higher capacity and can serve higher travel demand. The concept of PRT was introduced in 1953 as a result of research on alternative transportation modes. The first implementation of the system was at West Virginia University between campuses. It was called the Automated Group Rapid Transit system [23]. The Group Rapid Transit (GRT) and the Personal Rapid Transit (PRT) services are similar types of transit systems but the GRT serves a larger group of passengers and it is more often timetable-based. PRT vehicles are intended for the private use of a 'party' (traveling companions, i.e. a small group typically 1 to 6 passengers riding together by choice). The typical vehicle has maximum capacities of between three and six passengers, all seated. The stations are mostly off the guideway and the network usually includes extensive branching of

Table 1 Comparison of automated small and middle capacity transit modes (based on [22])

\begin{tabular}{|c|c|c|c|c|c|}
\hline & Monorail & LRT & GRT & APM & PRT \\
\hline Capacity & $>100$ & $>100$ & $8-20$ & $20-40$ & $3-6$ \\
\hline $\begin{array}{l}\text { Service } \\
\text { frequency }\end{array}$ & timetable & $\begin{array}{l}\text { time- } \\
\text { table }\end{array}$ & $\begin{array}{c}\text { mostly } \\
\text { timetable }\end{array}$ & $\begin{array}{l}\text { time- } \\
\text { table }\end{array}$ & $\begin{array}{c}\text { on- } \\
\text { demand }\end{array}$ \\
\hline $\begin{array}{l}\text { Operating } \\
\text { speed }[\mathrm{m} / \mathrm{s}]\end{array}$ & up to 138 & up to 29 & up to 29 & up to 22 & up to 15 \\
\hline Guideway & $\begin{array}{l}\text { suspended } \\
\text { rail }\end{array}$ & rail & rail & rail/road & $\mathrm{rail} / \mathrm{road}$ \\
\hline $\begin{array}{l}\text { Vehicle } \\
\text { type }\end{array}$ & $\begin{array}{l}\text { electric- } \\
\text { powered }\end{array}$ & $\begin{array}{l}\text { diesel/ } \\
\text { electric- } \\
\text { powered }\end{array}$ & $\begin{array}{l}\text { electric- } \\
\text { powered }\end{array}$ & $\begin{array}{l}\text { electric- } \\
\text { powered }\end{array}$ & $\begin{array}{l}\text { electric/ } \\
\text { battery- } \\
\text { powered }\end{array}$ \\
\hline
\end{tabular}

lanes (i.e. a lane that connects to the station and the main lane without connection to the station). The guideway is elevated, located at ground level or underground. The service is available on-demand 24 hours a day rather than on fixed schedules. The vehicles can switch from lane to lane and carry the passengers from their origin station to their destination station without intermediate stops [24]. Any of the guideway options can be implemented with the objective of capital cost reduction, obstacle avoidance such as building entrances, driveways, street intersections, underground barriers and most importantly to satisfy passenger and community needs and their preferences [25].

As the demand from parking to terminals is uneven, a service with a fixed timetable is not suitable. Furthermore, high capacity solutions such as APM are unnecessary. Based on just guideway costs, the use of small vehicles traveling at short headways is a trend to be encouraged. The headway can be reduced to minimize the waiting time and hence on the increase the patronage of the service [25]. That is why PRT service is recommended for implementing at airports providing shuttle service. The application of PRT at airports was already investigated in 90'. Poor and Steward [26] assessed the application of PRT for Seattle-Tacoma International Airport. They found that the financing issues and the lack of community support for the new automated technology are the main drawbacks. Muller [27] introduced a concept for the application of PRT at airports remote parking facilities to the airport terminal. After the comparison of PRT and APM, PRT was proved to be more efficient for shuttle service. In Muller's concept the security checking and baggage control were included at the shuttle service. In 2015, a prototype application of an airport PRT was implemented at the Heathrow airport, known as the ULTra (Urban Light Transport). The estimated mean passenger time saving for Heathrow is 8.4 minutes, or $60 \%$ of current transfer times [28]. The ULTra has proven to be efficient as it currently runs between Heathrow Airport Terminal 5 and parking facilities. In addition, shuttle bus and PRT service attributes were compared to decide whether shuttle bus or PRT service should be implemented in Greenville-Spartanburg International Airport [29]. The 30-year life cycle estimation showed that PRT is more prosperous from both passenger side (reduced travel time, on-demand) and operational side (reduced operational and maintenance cost, reduced $\mathrm{CO} 2$ emission). The net present worth (life cycle revenues minus costs discounted for inflation) of the PRT solutions is slightly higher than the bus solutions. 
In conclusion, airport ground access is an up-to-date, relevant topic. Researchers mostly focus on the modal share, travel time reduction and energy-efficient airport ground transfer. Though the general aim is to motivate the modal shift to public transport use, the current trend is that private car use is significant. That notwithstanding only a few pieces of research focus on the shuttle services for private car users. These papers highlight the efficient use of PRT service for connecting remote parking areas and terminal. However, the papers mostly considered the PRT service as a simple shuttle service without any advanced flight-related functions or the flight-related functions were mentioned on a superficial level. Moreover, the system planning principles considering passenger expectations of advanced PRT service has not been elaborated yet. Accordingly, a clear research gap can be identified as how the PRT service can be applied at airports with advanced, flight-related functions.

\section{Concept of advanced PRT service}

The system framework for the advanced PRT service was elaborated in order to reveal the information management components (subsystems) and the connections between them. Furthermore, the functional model was developed to identify the main tasks of the PRT system. The top to bottom approach was applied, firstly the subsystems, then the connections, and finally, the functions have been investigated, respectively.

\subsection{System model}

The elaborated system architecture is presented in Fig. 1. The components are connected to each other; data are transmitted between them. Accordingly, uninterrupted telecommunication is a major condition of the system. The data flow connections are illustrated by arrows. The numbers on the arrows represent the functions (The list of functions is given in the next section.). One number may be indicated

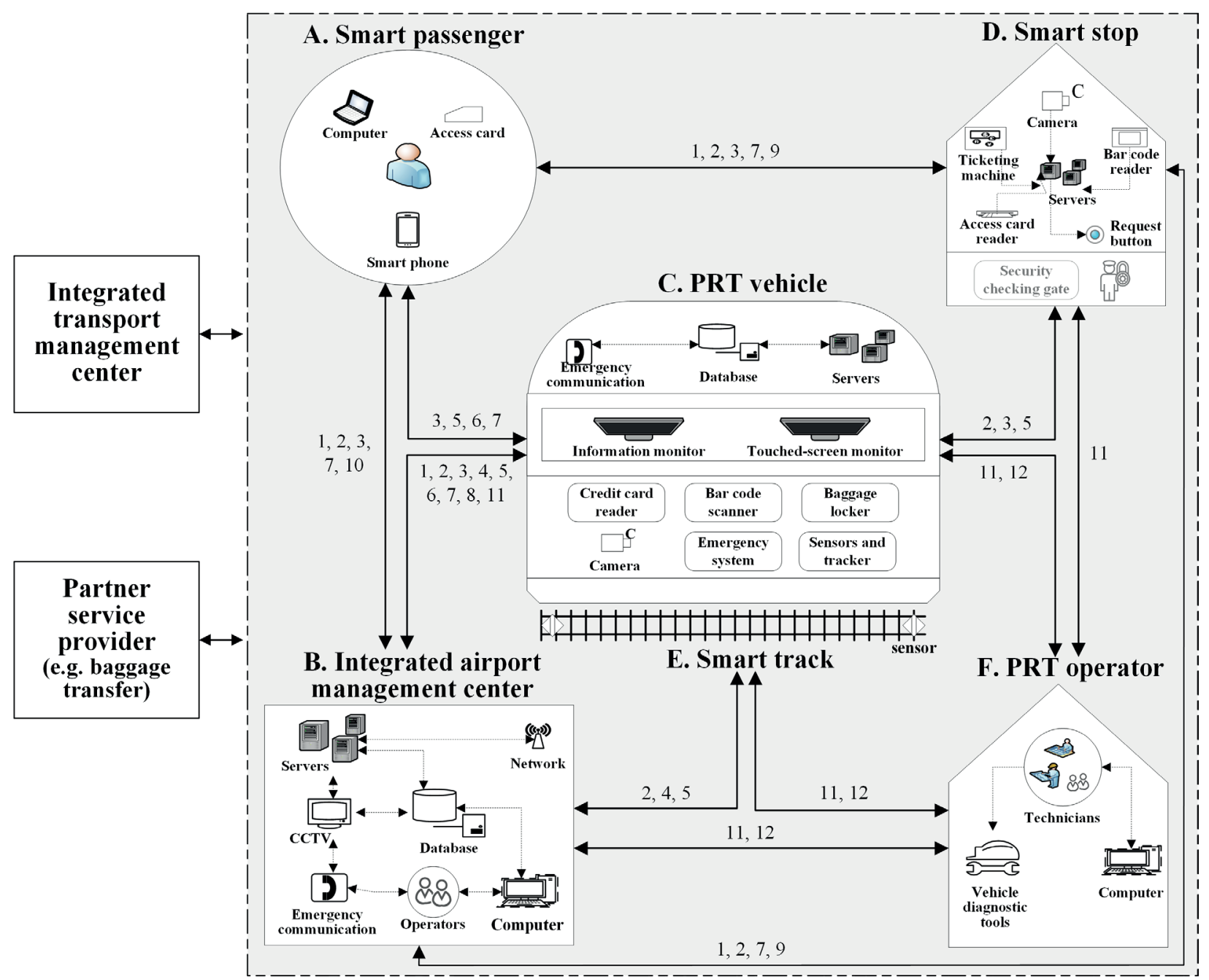

Fig. 1 System architecture with functions 
on several arrows if more than two components cooperate for one function. The hardware and technology elements are also shown in the figure. The following main components are distinguished:
A. smart passenger,
B. integrated airport management center,
C. PRT vehicle,
D. smart stop,
E. smart track,
F. PRT operator.

A. Passengers may use their smartphone to open the website or mobile application to obtain the right to gain access to the PRT service and to pay for it. So, the requirements for their cognitive capabilities are minimized. They may also order and pay for the service at the 'PRT station' (smart stop) using a ticketing machine.

B. The integrated airport management center manages the service (e.g. demand-capacity coordination) as a core element. The airport landside and airside operations, especially flight-related services, are integrated. The airport inbound flight traffic is monitored, and the demand is predicted and managed accordingly. The PRT vehicles are coordinated by the center, which is responsible for the planning, disposition, and control process of PRT vehicles.

C. The PRT vehicle runs on a smart track, senses the environment via sensors, processes the input data, and sends data to the management center(s). The system is rail-based and the vehicles are powered by a static (station-based) or a dynamic (along with the track) charging system. As vehicles are unmanned, several devices for passenger handling and information provision are installed in the vehicle. The PRT vehicles are connected to the management centers and stops (V2I) and to each other (V2V). Each vehicle is equipped with vandal-resistant materials, communication systems, emergency buttons, and primary ventilation system, also hardware elements for flight-related services. For instance, a touch-screen monitor is applied for checking-in, initiating the baggage check-in or serving special requests. Additionally, a locker box is installed for baggage handling.

D. Smart stops are equipped with advanced technology devices to enhance passenger experience and physical comfort. Accessibility for disabled persons is considered and supplementary services are provided. For instance, a bar code reader can be installed at the smart stop that gives the passenger access to the PRT vehicle. Some smart stops are equipped by off-line guideway to (un) load and store the PRT vehicles when they are not in use.
Additionally, security checking can be introduced at boarding stops; however, deploying security facilities and providing security staff at every stop are quite resource-intensive. Accordingly, security checking is proposed to be provided at the final station.

E. The smart track is equipped with various sensors and devices to collect and send operation-related data such as PRT vehicle position or to improve traffic safety [30]. The smart track detects foreign objects that may affect the operation and initiate emergency interventions.

F. The PRT operator is contracted to maintain and repair the PRT vehicles and smart track as well as to implement a smart-track control timely to measure the gauge and irregularities in cross-level, longitudinal level, and line.

However, to handle certain flight-related services, partner service providers should be involved. For instance, the baggage checked on-board in a PRT vehicle should be unloaded and taken from the PRT stop to the flight in a secure way right on time.

Moreover, two-way data transmission between the integrated airport management center and the integrated transportation management center may be incorporated into the system to deliver information about public transportation connections, including traffic updates. Intensive cooperation and data transmission between them are essential to provide real-time and forecasted information.

\subsection{Functional model}

The functions are represented in Fig. 2. The task of a component in each function is presented by a box. The same letters and numbers were used as in Fig. 1 to indicate the components and functions. The functions have been categorized into phases of the ride (before, during and after) and a supplementary phase.

Before the ride:

(1) Passengers set travel parameters (departure, destination, number of passengers, baggage handling, etc.) on a mobile application, or on interactive touch screen monitors installed at smart stops. All kinds of travelers (regular users, occasional users, and visitors) may select the travel parameters on the spot. The input data from the passengers are collected and processed by the integrated airport management center. (2) This center plans each ride by assigning the available vehicles on passenger request. Simultaneously, the center sends the disposition of the assigned vehicle to the passenger on the mobile application and at the smart stop (display screen) indicating the arrival time of the assigned vehicle. The PRT vehicle 
A

B
C

D

$\mathbf{E}$

$\mathbf{F}$

\begin{tabular}{|c|c|c|c|c|c|c|c|}
\hline \multirow{4}{*}{ 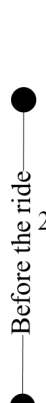 } & Functions & $\begin{array}{c}\text { Smart } \\
\text { passenger }\end{array}$ & $\begin{array}{l}\text { Integrated airport } \\
\text { management center }\end{array}$ & PRT vehicle & Smart stop & \multirow[t]{2}{*}{ Smart track } & \multirow[t]{2}{*}{$\begin{array}{c}\text { PRT } \\
\text { operator }\end{array}$} \\
\hline & 1. Ordering & $\begin{array}{l}\text { Set travel data } \\
\text { via phone/on stop }\end{array}$ & $\begin{array}{l}\text { Passenger-vehicle } \\
\text { assignment }\end{array}$ & Receiving task & Sending travel request & & \\
\hline & $\begin{array}{l}\text { 2. Tracking and } \\
\text { information } \\
\text { provision }\end{array}$ & $\begin{array}{l}\text { Receiving info about } \\
\text { PRT arrival }\end{array}$ & $\begin{array}{l}\text { Process input data, } \\
\text { provide real-time } \\
\text { information }\end{array}$ & $\begin{array}{l}\text { Sending position to } \\
\text { the center }\end{array}$ & $\begin{array}{l}\text { Receiving and display } \\
\text { PRT vehicle arrival } \\
\text { time, real-time } \\
\text { information }\end{array}$ & $\begin{array}{l}\text { Tracking vehicle } \\
\text { position }\end{array}$ & \\
\hline & $\begin{array}{l}\text { 3. Boarding/ } \\
\text { entitlement } \\
\text { check-in }\end{array}$ & $\begin{array}{c}\text { Ticket validation } \\
\text { (e.g. QR code scan), } \\
\text { verifying the boarding }\end{array}$ & $\begin{array}{c}\text { Sending PRT vehicle } \\
\text { assignment update }\end{array}$ & $\begin{array}{l}\text { Sending position and } \\
\text { executing travel }\end{array}$ & $\begin{array}{c}\text { Providing PRT } \\
\text { vehicle access based } \\
\text { on entitlement }\end{array}$ & & \\
\hline & 4. Control & $\begin{array}{l}\text { Receiving info about } \\
\text { position/arrival time } \\
\text { (V2N) }\end{array}$ & $\begin{array}{c}\text { Data exchange } \\
\text { between centers; } \\
\text { managing the route }\end{array}$ & $\begin{array}{l}\text { Sending position to } \\
\text { the center/ } \\
\text { other vehicle (V2V) }\end{array}$ & & $\begin{array}{l}\text { Tracking vehicle } \\
\text { position (V2I) }\end{array}$ & \\
\hline & 5. Emergency & $\begin{array}{c}\text { Activating emergency } \\
\text { device }\end{array}$ & $\begin{array}{c}\text { Receiving emergency } \\
\text { message, managing } \\
\text { the situation }\end{array}$ & $\begin{array}{l}\text { Sending emergency } \\
\text { message, activating } \\
\text { emergency procedure }\end{array}$ & $\begin{array}{l}\text { Sending emergency } \\
\text { message, activating } \\
\text { emergency procedure }\end{array}$ & $\begin{array}{l}\text { Activating } \\
\text { emergency } \\
\text { procedure }\end{array}$ & \\
\hline & $\begin{array}{c}\text { 6. Flight-related } \\
\text { services } \\
\text { (ticket purchase, } \\
\text { check-in, baggage }\end{array}$ & Request a service & $\begin{array}{c}\text { Managing requests } \\
\text { (e.g. organize unloading } \\
\text { and transfer of baggages) }\end{array}$ & $\begin{array}{l}\text { Receiving and } \\
\text { sending services } \\
\text { request }\end{array}$ & & & \\
\hline & 7. Payment & $\begin{array}{l}\text { Confirmation of } \\
\text { payment via phone/ } \\
\text { on-board unit }\end{array}$ & $\begin{array}{l}\text { Fare calculation, } \\
\text { managing payment } \\
\text { process }\end{array}$ & $\begin{array}{l}\text { Sending payment } \\
\text { confirmation data }\end{array}$ & $\begin{array}{l}\text { Accepting trip } \\
\text { payment (e.g } \\
\text { membership card) }\end{array}$ & & \\
\hline & 8. Alighting & & $\begin{array}{c}\text { Receiving and processing } \\
\text { update of PRT vehicle; } \\
\text { manage luggage delivery }\end{array}$ & $\begin{array}{l}\text { Detecting alightment, } \\
\text { update the status }\end{array}$ & & & \\
\hline 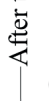 & $\begin{array}{c}\text { 9. Flight-related } \\
\text { services } \\
\text { (security checking) }\end{array}$ & Identification & $\begin{array}{l}\text { Controlling the } \\
\text { process }\end{array}$ & & $\begin{array}{c}\text { Providing the } \\
\text { infrastructure; sending } \\
\text { data about securty gates }\end{array}$ & & \\
\hline & $\begin{array}{c}10 . \\
\text { Evaluation, } \\
\text { feedback }\end{array}$ & $\begin{array}{l}\text { Rating the service, } \\
\text { sending feedback }\end{array}$ & $\begin{array}{c}\text { Evaluation of service, } \\
\text { and upgrade }\end{array}$ & & & & \\
\hline 冚 & $\begin{array}{l}11 . \\
\text { Maintenance }\end{array}$ & & $\begin{array}{l}\text { Planning and } \\
\text { assigning }\end{array}$ & $\begin{array}{l}\text { Sending diagnostics } \\
\text { data }\end{array}$ & & $\begin{array}{c}\text { Sending } \\
\text { diagnostics data }\end{array}$ & $\begin{array}{l}\text { Vehicle/track } \\
\text { maintenance }\end{array}$ \\
\hline$\frac{\overline{0}}{\stackrel{2}{\bar{Z}}}$ & 12. Repair & & $\begin{array}{l}\text { Coordinate repair } \\
\text { service and } \\
\text { replacement }\end{array}$ & $\begin{array}{l}\text { Indication of } \\
\text { technical fault }\end{array}$ & & Fault detection & $\begin{array}{l}\text { Fault detection, } \\
\text { and repair }\end{array}$ \\
\hline
\end{tabular}

Fig. 2 Functional model

receives the task and sends its position to the integrated airport management center to inform the passenger of the vehicle proceeding.

(3) At the selected arrival stop, a barrier is installed between the vehicle and the passenger. The barrier is enabled with an identification verification technology (e.g. QR code scanner). The passenger is required to verify the code generated for the journey. After successful authentication, the barrier and the PRT vehicle door open enabling the passenger to board the vehicle. The passenger is engaged to verify the successful boarding to start the ride. The operation and airport management center receive an update that the passenger is seated, and the travel has begun.
During the ride:

(4) Data are constantly exchanged between the center and the PRT vehicle. Accordingly, the route is recalculated, and the estimated arrival time is updated using an advanced vehicle to infrastructure (V2I) communication system. PRT vehicles are designed to send position data to each other using vehicle-to-vehicle (V2V) short-range communication to avoid a collision. Partially automatized vehicles with V2V/V2I communication are also eligible to take part in an automatized traffic system [31].

(5) In the case of emergency, the in-built emergency devices can be used by the passengers or the specific situations, such as overheating, power shortage, collision are to be detected by the infrastructure. With the aid of 
V2I communication, the center is also able to manage the emergency as the vehicles are semi-autonomous. The smart stop and smart track are also equipped with emergency devices to manage vehicle malfunction. After processing the data and identifying the emergency circumstances, data is sent automatically to the integrated airport management center and the interventions are initiated.

(6) Flight-related services are integrated into the PRT vehicle. Passengers can request and pay for flight-related services onboard such as check-in, special assistance, baggage handling, etc. The baggage handling service can be requested by a passenger via smartphone, at the smart stop or during the ride; the passenger should make the order in advance. A special baggage box can be installed on-board in which the passenger may leave the baggage. To ensure a smooth end-to-end process of baggage handling, the flight number is to be given by the passenger. The integrated airport management center transfers data about flight details, boarding gate, terminal, etc. to the partner service provider. Therefore, the passenger may alight from the PRT vehicle without his baggage; the baggage is delivered to the flight. Human staff, namely the contribution of a partner service provider may be needed to take the baggage from the PRT vehicle to an automated bag drop-off system or directly to the airplane.

After the ride:

(7) The fare calculation and payment processes are managed. The passengers pay via mobile phone, or vending machines are installed at the stops. (8) After alighting, the vehicle is reassigned for the next ride. (9) The security checking as a flight-related service is part of the advanced PRT service. At the final station, an exclusive security checking station is installed. Leaving the stop is possible only after a successful payment and security check. (10) The passengers can evaluate the quality of the service and give feedback. The feedback is processed and stored in the database of the center and then used to improve the service.

\section{Supplementary activities:}

(11-12) Maintenance and repair are coordinated by the integrated airport management center. The vehicle and the smart track provide diagnostic data quasi-continuously. In the case of technical breakdown, the disabled vehicle may be replaced by another or the disposition of the available vehicles are modified.

The advanced PRT service can be used from the terminal to reach the parking facilities as well; however, the flight-related services are not available in this direction.
For instance, passengers should pick up the baggage in the traditional way, because baggage management by a service provider is rather difficult due to the short time spent at the airport.

In summary, the major tasks of the integrated airport management center are to handle passenger data and travel parameters, provide personalized information, plan, organize and control the processes, manage flight-related services and payment, evaluate the service and assure the quality of the entire PRT service.

In the developed concept, the provided flight-related services are wide-range (e.g. check-in, ordering food) comparing to Muller's concept [27]. Furthermore, the security check is accomplished at the final stop at the terminal after the passenger gets off the vehicle. In Muller's concept the travelers are seated in the vehicle during the security check which is accomplished in dedicated screening facilities. This solution is less efficient; more PRT vehicles are needed as the vehicle is occupied during the security check, moreover, building additional security facility is needed.

Advanced PRT service is an ideal solution for airports with isolated parking facilities farther from the terminal (e.g. Beijing Capital International Airport, London Heathrow, Dubai International Airport), and airports whereby the walking distance between parking facility and terminal is significant. Initiating an advanced PRT service may serve as a motivation for an airline to seek changes in the functionality of terminal facilities as well. In addition, the concept of the onboard flight-related service has the potential to reduce waiting in a consolidated concession area; thus, it helps to refine the airport transit operation. The passenger of advanced PRT service can skip several flight-related services and can walk directly from the PRT station to the waiting hall.

\subsection{Comparison of airport surface access types}

The ground access to an airport, the flight-related services before boarding the airplane, and the used transportation means are presented in Fig. 3. The numbers have been used to identify each of the airport surface access forms. In the case of general forms (1-4), the passengers need to walk between flight-related services and wait at each stop. This walking phase starts from the drop off point in the case of using public transportation (1), taxi (2) or the combination of the private car and shuttle bus (3). In these cases, the egress walking from the drop off point to the entrance of the terminal is minimal. However, using the private car without a direct shuttle service (4), the egress walking 
distance is longer. If a regular PRT or APM (5) is operated between parking facilities and terminal, the egress walking is minimal, but the passengers need to walk during flight-related services.

The proposed integrated solution serves the landside operation of the airport, connecting the car park and the airport terminals and to serve flight-related services on-board minimizing the time consumption. The advanced PRT (6) serves and eases the activities of air passengers and airport operators.

The airport ground access forms were compared according to basic properties (see column headers) in Table 2. These are commuting time, waiting time, walking distance of the passenger from the drop-off point to the boarding gate, cost of transportation and comfortability. The forms are indicated in rows by numbers. The amount of symbol "+" indicates the strength of a property (+: low/small; +++++: high/big).

Public transportation (1) is the most cost-effective; however, the walking distance, commuting time and waiting time are high enough. More so, it provides less comfort for commuters; hence, it is not the most suitable option for air passengers that mostly travel with big baggage. Similarly, taxi (2), shuttle bus and personal car (3) have shorter waiting times because their services are more flexible than public transportation and may deliver the passengers

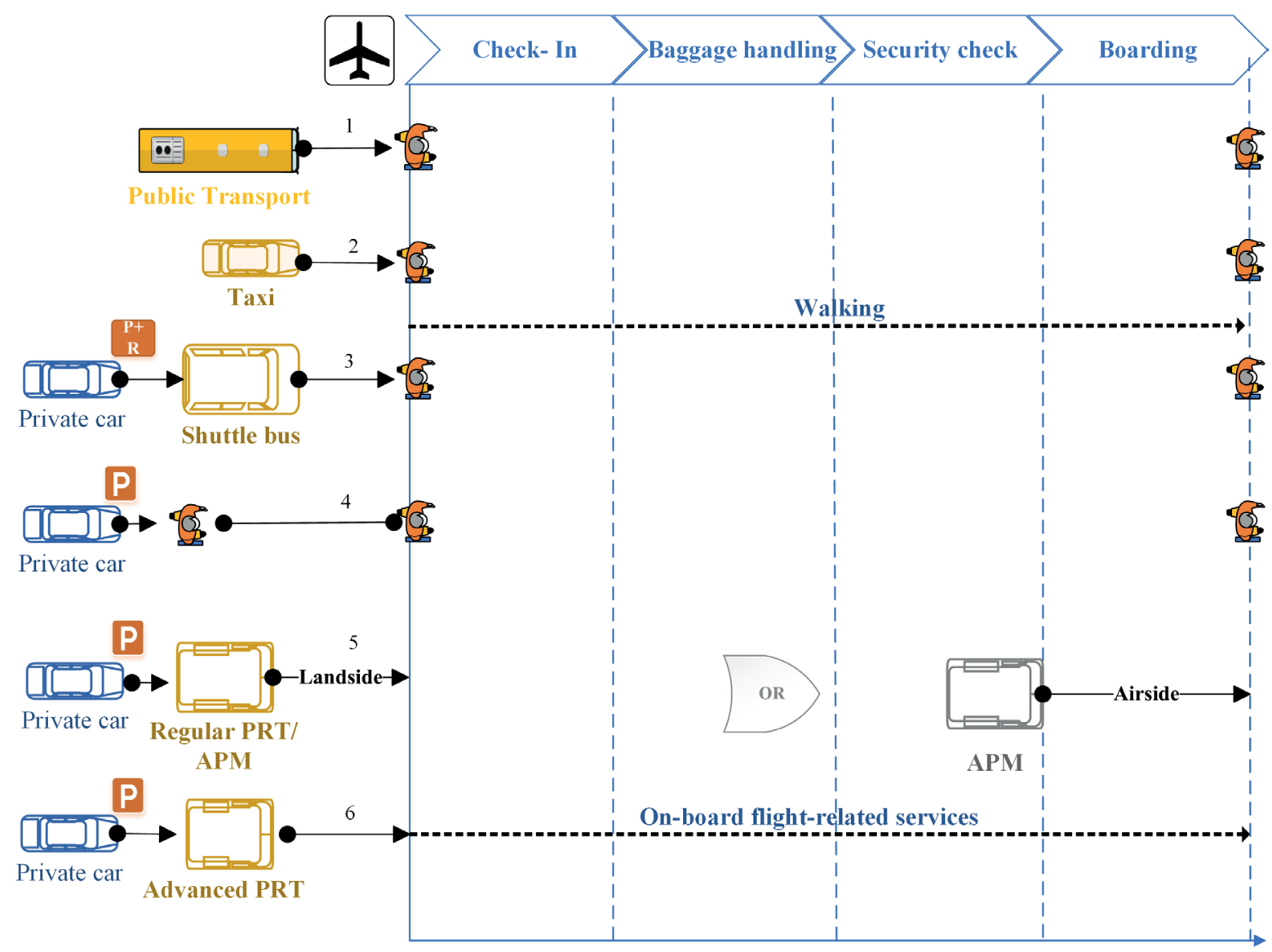

Fig. 3 Airport ground access types

Table 2 Comparison of airport ground access forms

\begin{tabular}{|c|c|c|c|c|c|}
\hline Mode & Commuting Time & Waiting Time & Walking Distance & Cost & Comfort \\
\hline 1. Public transportation & ++++ & ++++ & ++++ & + & + \\
\hline 2. Taxi & +++ & +++ & ++++ & +++++ & ++ \\
\hline 3. Private car and shuttle bus & +++ & ++ & ++++ & ++++ & ++ \\
\hline 4. Private car & +++ & + & +++++ & ++ & + \\
\hline 5. Private car and regular PRT/APM & ++ & ++ & +++ & ++++ & +++ \\
\hline 6. Private car and advance PRT & ++ & + & + & +++ & +++++ \\
\hline
\end{tabular}


closest to the airport terminal entrance. Although, the personal car may be less comfortable in comparison to a taxi because of the difficulty in finding a parking spot near the terminal entrance which may lead to long walking distance (4). The regular PRT/APM (5) and advanced PRT (6) provide similar commuting time and prices, the least walking distance in comparison to other modes and provide the highest comfort. Furthermore, advanced PRT offers an improved service in terms of walking distance, waiting time and better comfort compared to the regular PRT/APM modes in accessing the airport terminals. Due to the on-board flight-related services, it is the most suitable model amongst other options.

Though the aim of advanced PRT service is to improve the user satisfaction and travel quality, revealing of user expectations and judgments are needed as behavioral intentions are mostly affected by passengers' judgments about the quality of a mobility service [32].

\section{User expectations}

A questionnaire survey was performed to collect expectations towards the proposed PRT service. A general questionnaire was prepared which can be applied at any airport; however, some airport-related questions are unavoidable. The questions are focused on travel habits, expectations, and the potentials of using PRT service.

Parts of the questionnaire:

- personal questions regarding the age group and income (1-3 questions),

- travel habit questions regarding the used mode and frequency of air-traveling (4-13 questions),

- PRT questions regarding the expectations towards the services (14-21 questions).

The questionnaire was tested on the spot in person at Budapest Liszt Ferenc International Airport (BUD); thus, the participants were able to ask questions to clarify their understanding of the proposed service. Some of the questions were Simple-multi-choice ones, participants expressed their opinion by choosing one from among the given options. Other questions were ranking scale choices, so-called Likert-scale, the participants were asked to rank alternatives from the most important to the least, thus allowing us to identify participant preference order for all alternatives. Indeed, one survey needed about 25 minutes to complete. Images of the Heathrow airport ULTra pods and Budapest airport layout were used to give a visual representation of the proposed service.
Though the survey was not representative, initial consequences can be drawn about the expectations. The survey result is not normally distributed data. Normality was not examined as it cannot be derived from Likert-scale question types. 100 air travelers were interviewed.

The following generations are distinguished: $14.3 \%$ of respondents belong to the Baby Boomer generation (born 1946-1960), 33.7 \% are Generation X (born 1961-1980), and $52 \%$ are the most current Generation Y, so-called Millennials (born after 1980) [33]. Their profession and income were considered for further analysis. It is a recognized fact that the main socio-economic factors that influence the frequency of travel are the income level and the purpose of travel.

As the advanced PRT connects parking facilities and terminals, the survey focused on car users. $36 \%$ of the respondents use their personal car to commute to the airport. On the other hand, $14 \%$ of the respondents use a personal car as a passenger without using any parking facility, $20 \%$ use taxi, $11 \%$ use shuttle bus (MiniBud), $3 \%$ use the express public bus (100E) from the city center, and $16 \%$ use the feeder public bus service (200E) from the nearest metro station.

Generation Y shows greater familiarity than the previous generations with communication, media, and digital technologies. The result in Table 3 interprets the study of generational diversity towards a willingness to use the advanced PRT. Advanced PRT service can be considered as a technological novelty that is why the millennials are willing to use the PRT more than the other generations.

According to the survey, participants are willing to pay a mean price of 3.4 Euro per ride for the PRT service. $24 \%$ of the participants mentioned that the price was considered based on the charges for parking at the airport which ranges from 10-100 Euro per day depending on how far the parking facility is located to the terminal. For comparison, public transportation ticket costs about 1 Euro per trip and about 3 Euro for an express bus ticket. $4 \%$ of the participants prefer that the PRT service charge is included in the parking ticket, $26 \%$ prefer it to be included in flight tickets, and $50 \%$ prefer that the PRT service should be charged independently.

Table 3 Willingness to use the PRT according to their generation [\%]

\begin{tabular}{lccc}
\hline Generation & yes & no & not sure \\
\hline Millennials & 70.6 & 2.0 & 27.5 \\
Generation X & 66.7 & 3.0 & 30.3 \\
Baby boomer & 57.1 & 0.0 & 42.9 \\
\hline
\end{tabular}


Fig. 4 shows the expectations towards flight-related and other supplementary services. Over $50 \%$ of the respondents perceive information provision about PRT arrival time, flight details and transfer connection as a very important feature that should be implemented in the vehicle. More than $60 \%$ of the respondents considered baggage handling and check-in function rather important as the passengers are mostly concern about avoiding long waits and check-in processes while fast food order and advertisement are deemed to be not important.

The respondents' willingness to use the service is the most significant if they have big luggage or if the weather is bad ( $80 \%$ of the respondents chose advanced PRT with high certainty). However, long walking distance is not a deterrent factor of walking. If the walking distance is long (higher than $500 \mathrm{~m}$ ), only $55 \%$ of the respondents may choose the advanced PRT service. If the PRT is faster than walking, its willingness of use is $90 \%$; however, $35 \%$ of the respondents hesitate and consider other factors (for instance weather, luggage size) as well.

The results were used to examine potential PRT users' behavioral intentions. Considering realistic users' expectations during the development of PRT layout and service may increase the level of perceived service quality. For instance, as respondents with lower income, especially millennials were more price-sensitive, they would usually patronize services based on lowest price and may have different levels of expectations. If the distance to the terminal from a PRT stop is less than 500 meters, young passengers with low-income would prefer to walk rather than to pay for a PRT service. Therefore, the results gathered from the survey were considered during the determination of neces- sary PRT stops and its connection to the parking facilities (e.g. stops only further from $500 \mathrm{~m}$ from the terminal, reaching a stop within $500 \mathrm{~m}$ walking in a parking facility).

\section{Layout selection method - a case study at Budapest Airport (BUD)}

In general, several remote parking facilities are located around the airport. The network of advanced PRT system connecting these facilities and the terminal has several possible variations. A method was developed for the selection of appropriate layout. The proposed layouts were developed based on consultation with the airport ground operation specialist. For instance, some parking facilities were omitted because of their short walking distance to the terminal or to the nearest parking facility with a PRT stop. The layout selection method was applied in Budapest Airport which is one of the fastest-growing destinations for tourism. This has resulted in the development and growth of the airport terminal and operation including an increase in the usage of the parking facilities. However, the shuttle service between the remote parking facilities and terminal is not well developed yet.

\subsection{Selection method}

A multicriteria analysis method was developed which can be applied to evaluate alternatives for the purpose of selection or ranking. This method is appropriate to evaluate previously proposed PRT layouts. The objective of the multicriteria analysis technique is to serve as the resolution of planning problems. One of the most used and wellknown multicriteria techniques is the Analytic Hierarchy Process (AHP), developed by Saaty [34, 35].

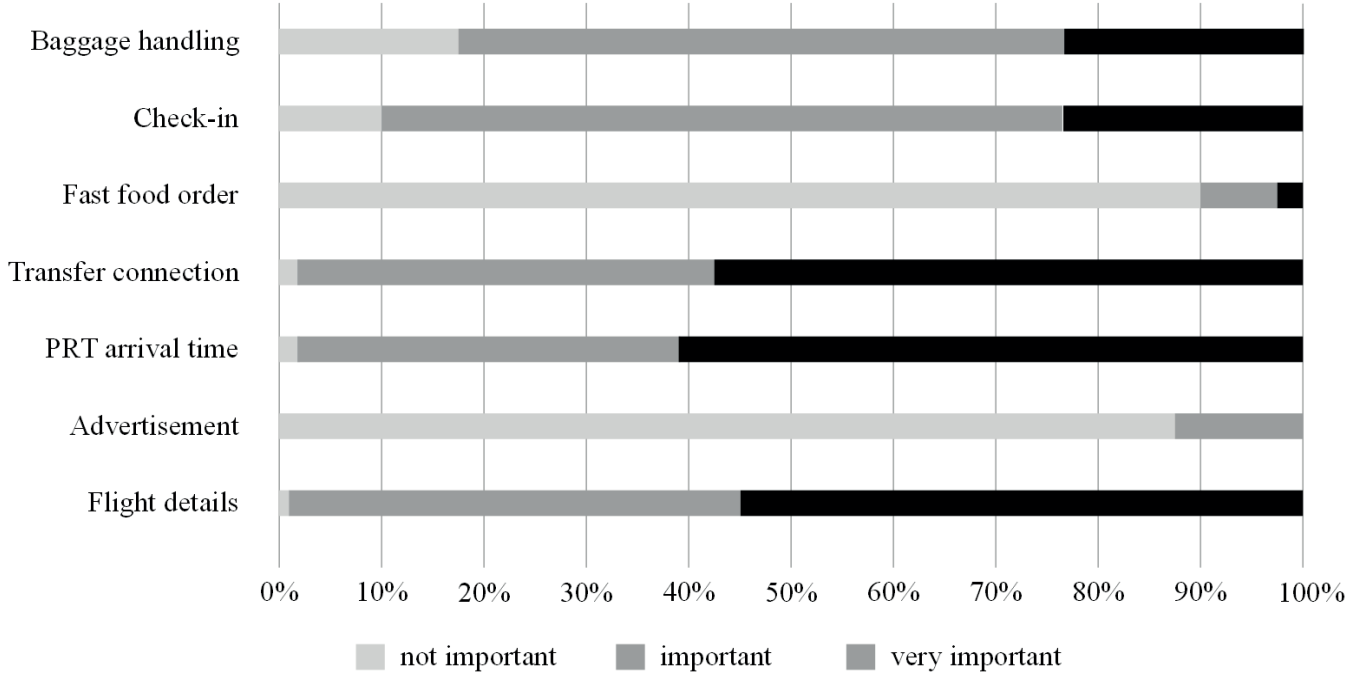

Fig. 4 Importance of on-board services 
Steps of AHP:

- decomposition,

- prioritization,

- synthesis,

- sensitivity analysis.

The values selected for the pairwise comparison are numbers ranging from 1 to 9 which indicate the intensity of importance: 1 - equally important, 3 - moderately important, 5 - strongly important, 7 - very strong or demonstrated important, 9 - extremely important, and $2,4,6,8$ - are interpolation between the odd values [34]. The motivation behind the development of the method is to propose a generalized method based on belief functions recommended by academic and professional experts.

Step 1: We gave the judgment based on the pairwise comparison scale according to Eq. (1). It is a reciprocal matrix where all the elements are positive. It contains the derived pairwise comparison, $a_{i j}=w_{i} / w_{j}\left(w_{i}\right.$ and $w_{j}$ are the relative importance of the criteria $i$ and $j$, respectively), their reciprocal, $a_{i j}=1 / a_{i j}$, and diagonal elements $a_{i j}=1$. Pairwise comparison is done only on half of the matrix.

$$
A=\left[\begin{array}{lll}
a_{11} & a_{12} & a_{1 n} \\
a_{21} & a_{22} & a_{2 n} \\
a_{n 1} & a_{n 2} & a_{n n}
\end{array}\right]=\left[\begin{array}{ccc}
1 & w_{1} / w_{2} & w_{1} / w_{n} \\
w_{2} / w_{1} & 1 & w_{2} / w_{n} \\
w_{n} / w_{1} & w_{n} / w_{2} & 1
\end{array}\right]
$$

Step 2: Afterward, we multiplied matrix $A$ with a vector of weights $W$ as shown in Eq. (2).

$$
A W=\left[\begin{array}{ccc}
1 & w_{1} / w_{2} & w_{1} / w_{n} \\
w_{2} / w_{1} & 1 & w_{2} / w_{n} \\
w_{n} / w_{1} & w_{n} / w_{2} & 1
\end{array}\right]\left[\begin{array}{l}
w_{1} \\
w_{2} \\
w_{n}
\end{array}\right]=n\left[\begin{array}{l}
w_{1} \\
w_{2} \\
w_{n}
\end{array}\right]=n W
$$

Step 3: If decision-makers' judgments are perfectly consistent in which all pairwise comparisons are equal to $a_{i k}=a_{i j} \times a_{j i}($ for $i, j$, and $k=1,2,3, \ldots, n)$, then the principal right eigenvector of $A$ is equal to $n$. For instance, comparing the number of stations allocated in the layouts are the same, which means the element cannot be compared as it is equal in all alternatives. However, in real-life perfectly consistent judgement is rare, so that the eigenvalue of $A$ equals to $n$ is also rarely happens. Therefore, the largest eigenvalue $\gamma_{\max } \geq n$ and Eq. (2) is transformed into Eq. (3).

$$
A W=\gamma_{\max } W
$$

Step 4: The weight $W$ is calculated through the normalization process of the columns in matrix A, as shown in Eq. (4).

$W_{i}=\frac{a_{i j}}{\sum_{k=1}^{n} a_{k j}}$

The evaluation is based on the guideway layout considering the influencing factors, such as distance, accessibility from the terminal, guideway obstruction, and delay reduction. These factors are easily available factors that can be measured with the data and information received from an airport authority. The distances are calculated based on the layout. Accessibility from the terminal is used to compare how much it takes a passenger to reach the nearest PRT station from the terminals. Guideway obstruction indicates the interference between the airport facilities, road network and the tracks. The delay reduction is the approximate time delay that may occur in a ride due to a junction in the layout.

This hierarchy of decision-making analyses is one of the basic methodologies in choosing a transportation service. Our aim was to plan the basic network for the PRT implementation. The main aspects are considered from a user side only.

\subsection{Layout determination}

According to the Budapest airport parking area scheme and structure, holiday parking is designed for long term usage and it costs less to use in comparison with other parking facilities. The capacities of different parking facilities are holiday parking 2525 cars, business parking 129 cars, and central parking 255 cars, respectively. Although the capacity of the central parking, which has the shortest distance to the terminal, is high, the annual average usage is lower than others. As it is designed for short term use, the parking fees are rather high.

The transit demands are served by shuttle buses or on foot from the parking area to terminals. The farthest parking area is the 'holiday lite parking' which is situated about 12 minutes' (900 meters) walk away from the airport terminal. However, a shuttle bus operates only from the business parking while other parking facilities have no transit service. The shuttle buses operate at relatively high frequency. The ongoing shuttle service requires preordering via phone call or mobile application; however, this is not a fully demand-driven service as the passengers must wait several minutes. Moreover, a relatively long walking distance is needed to the stops. 
In recent times, there have been plans to improve the airport. Constructions are currently ongoing in the central parking area to expand its capacity. However, the role of farther parking facilities is not influenced by the construction.

The proposed PRT service layouts are shown in Fig 5. The alternatives were created considering user preferences (minimized walking distance, availability of parking facilities, shorter travel time comparing with walking time), sight-visits and consultation with airport ground operations authorities. The basic principle was to connect every parking area to the terminal in each alternative.

The alternatives are indicated by different colors. The stations are indicated with a sign and labeled respectively. On the airport layout, there is a hotel located a few meters away from the Central Parking, passengers going to and from the hotel are assigned to use the PRT service on the Central Parking station. The alternatives do not serve the central parking area (currently, it is a construction site) because it is located very close to the terminal.

\subsection{Results}

Step 1: The elicitation of pairwise comparison judgments and the scale derived from Eq. (1) are given in Table 4. Five experts from academic, airport operation and ground operation were asked to evaluate the layouts; the table represents the aggregated values given by the experts. The scale is validated to show effectiveness through

Table 4 Pairwise comparison matrices

\begin{tabular}{cccc}
\hline \multicolumn{4}{c}{ Distance } \\
& $\mathrm{A}$ & $\mathrm{B}$ & $\mathrm{C}$ \\
\hline $\mathrm{A}$ & 1 & 3 & 7 \\
$\mathrm{~B}$ & 0.33 & 1 & 5 \\
$\mathrm{C}$ & 0.14 & 0.2 & 1 \\
\hline \multicolumn{4}{c}{} \\
\hline \multicolumn{4}{c}{ Delay reduction } \\
\hline $\mathrm{A}$ & $\mathrm{A}$ & $\mathrm{B}$ & $\mathrm{C}$ \\
$\mathrm{B}$ & 7 & 0.14 & 0.20 \\
$\mathrm{C}$ & 5 & 3 & 0.33 \\
\hline
\end{tabular}

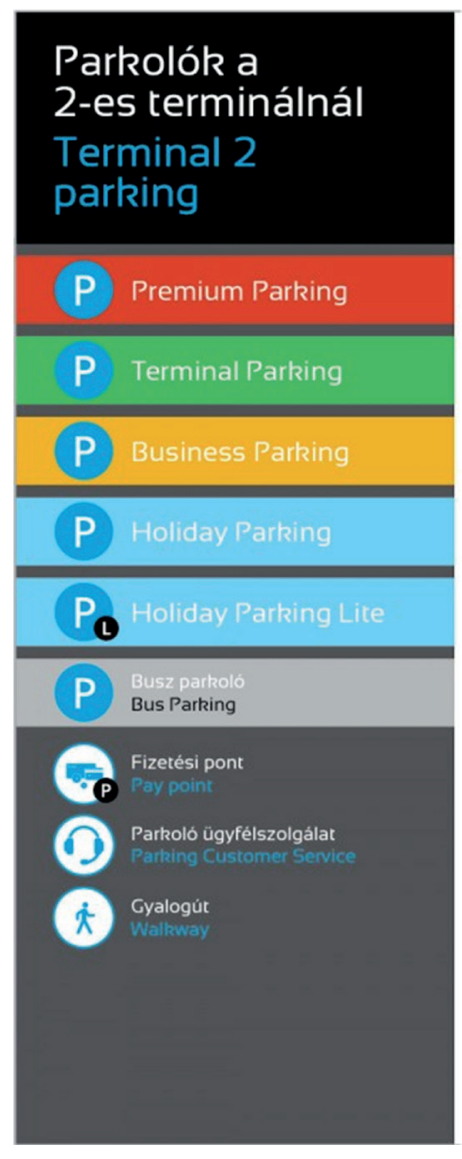

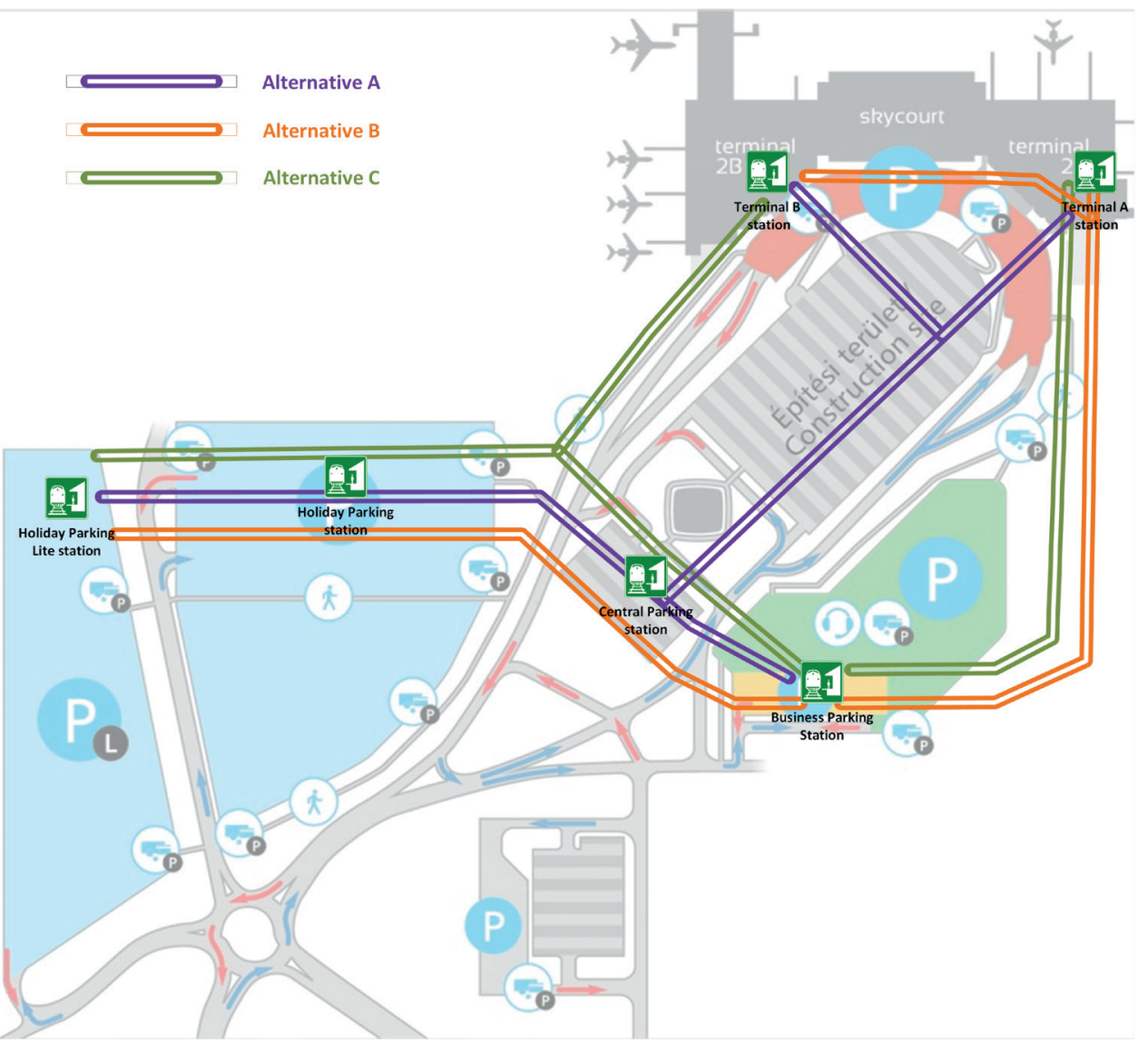

Fig. 5 Proposed PRT service layout for Budapest airport 
theoretical comparison. The importance of the criteria is necessary to be considered during the comparison of them to implement a sustainable service. According to distance (i.e. the distance from farthest stop to the terminals) as a decision criterion, we supposed that alternative $\mathrm{A}$ is much better than alternative $\mathrm{B}$, and alternative $\mathrm{C}$ is the least desired. Considering the accessibility (i.e. the convenience of accessing the boarding gate in the terminal from the PRT stop), even though all PRT stops are the same, in case of alternative the access from the parking facilities to terminal $2 \mathrm{~B}$ is easier. According to delay reduction (i.e. the amount of intersection on a guideway could impact the speed of the PRT vehicle), alternative $\mathrm{B}$ is preferable. Considering guideway obstruction (i.e. the possible obstruction of existing structures with the PRT guideway), alternative $\mathrm{B}$ and $\mathrm{C}$ are better than alternative A.

The values in Table 4 are derived by a cross rating of each alternative under the examined elements. For instance, in the Distance table, value 3 in the intersection of row A and column B means that alternative A is rated as moderately important in distance than alternative $\mathrm{B}$ and when comparing alternative $\mathrm{B}$ to alternative $\mathrm{A}$ the inverse of the rating is calculated resulted in $0.33(1 / 3)$. A similar interpretation is true for the rest of the entries.

Step 2: The weight preferences of each alternative respect to the considered element with the use of Eq. (2) are shown in Table 5.

The weighting preference is derived by the geomean of each alternative. For instance, the weight of alternative A is 2.76 for distance element; it is derived by the cube root of the product of all ratings on row alternative $B(1,3,7)$. After Eq. (4) is used, the weight of alternative $A$ (2.76) is divided by the sum of all alternatives $(\mathrm{A}, \mathrm{B}, \mathrm{C})$ and converted to a percentage value $(65 \%)$. This means that alternative $A$ is $65 \%$ preferred to other alternatives in terms of distance. A similar interpretation is true for the rest of the entries.

Table 5 Weight preferences

\begin{tabular}{|c|c|c|c|c|c|}
\hline \multicolumn{3}{|c|}{ Distance } & \multicolumn{3}{|c|}{ Accessibility from terminal } \\
\hline A & 2.76 & $65 \%$ & A & 1.19 & $25 \%$ \\
\hline B & 1.19 & $28 \%$ & $\mathrm{~B}$ & 1.00 & $22 \%$ \\
\hline $\mathrm{C}$ & 0.31 & $7 \%$ & $\mathrm{C}$ & 2.47 & $53 \%$ \\
\hline \multicolumn{3}{|c|}{ Delay reduction } & \multicolumn{3}{|c|}{ Guideway obstruction } \\
\hline A & 0.31 & $7 \%$ & A & 0.34 & $9 \%$ \\
\hline B & 1.33 & $33 \%$ & $\mathrm{~B}$ & 1.19 & $30 \%$ \\
\hline $\mathrm{C}$ & 2.47 & $60 \%$ & $\mathrm{C}$ & 2.47 & $61 \%$ \\
\hline
\end{tabular}

Step 3: To synthesize all priorities, the various priority vectors are weighted by the global priorities of the criteria and synthesized. The final relative priorities for the elements are obtained by giving a criteria score derived from the survey results. The score is a relative number, expresses the importance of the criteria for potential users. These indicate the degree to which the elements contribute to the main goal of the advanced PRT service.

This method follows the main principle of the simple addictive method. In simple addictive weighting, the weight of the criterion $j$ could be interpreted as a proportion of criterion $j$ in 1 unit of overall value. It can be expressed in percentage as well.

Step 4: Integrating the alternative matrix of the weighted preference and the criterion matrix, a subjective judgment on each alternative relative to all criteria is obtained in Table 6 which were derived according to Eq. (4).

Accordingly, alternative $\mathrm{C}$ is the best layout followed by alternative B. Planning of an effective transit system should proceed from a lucid perspective of the system objective. The main objective to be considered is to improve the accessibility, in terms of travel time and comfort. However, sometimes a quid pro quo is involved in the improvement of service. For instance, travel time and comfort can be ameliorated but only at a cost that the user or investor needs to bear. The proposed alternative $\mathrm{C}$ would evidently save travel time from the terminal to stops. For instance, travel time from the Holiday Parking station to terminal 2B would be the shortest. Alternative C passes through the side of the main airport area to avoid major obstructions. Although alternative $\mathrm{C}$ has one junction which may cause delays but better than alternative A with two junctions. Taking all the aspects into consideration, alternative $\mathrm{C}$ is the best option.

During the situation analysis, other proposals for the improvement of BUD airport accessibility arose. The construction of a ground mobility center (conductive bus stop) near to the airport area is advised to consolidate public transportation service. Accordingly, congestion at the terminal curb-front can be reduced. The facility can be linked by an automated guideway transit to the air terminal.

Table 6 Importance of criteria

\begin{tabular}{lc}
\hline Criteria & Importance \\
\hline Distance & 0.2 \\
Accessibility from terminal & 0.15 \\
Delay reduction & 0.25 \\
Guideway obstruction & 0.4 \\
\hline
\end{tabular}


This proposal would provide an environment in which waiting for scheduled service is more comfortable. Furthermore, it could also be linked with the planned train station. Low occupancy public services and private vehicles may use the curb-front also in the future as they provide door-to-door service at a relatively high cost.

\section{Conclusions}

PRT service is one of the most suitable airport shuttle forms; the service reduces the long waiting and walking time caused by the increment in flight rate, airport expansion, and isolated remote parking facilities. The research uncovers the concept of the advanced PRT system which serves both landside and airside activities and provides seamless transit by incorporating flight-related services.

The main contributions are the concept, namely the system architecture and functional model of the proposed service. Accordingly, the information management activities of the components are described. Several advanced features such as baggage handling and on-board services were proposed based on the perception of air passengers' expectations. AHP (Analytic Hierarchy Process) method was used to evaluate proposed PRT system layouts. The method was applied at Budapest Airport considering the expected quality of the PRT service connecting all parking facilities and terminals. Implementation of the

\section{References}

[1] Grimme, W., Berster, P., Gelhausen, M. (eds.) "Topical Report Airport Accessibility, Analyses of the European air transport market Airport Accessibility in Europe in Europe", [pdf] European Commission, Cologne, Germany, Final report 1.02, 2010. Available at: https:/ec.europa.eu/transport/sites/transport/files/modes/air/ studies/doc/intermodality/2010-airport-accessibility-in-eu.pdf

[2] Rodier, C. J., Johnston, R. A., Shabazian, D. R. "Evaluation of advanced transit alternatives using consumer welfare", Transportation Research Part C: Emerging Technologies, 6(1-2), pp. 141-156, 1998.

https://doi.org/10.1016/S0968-090X(98)00013-8

[3] Carnegie, J. A., Voorhees, A. M., Hoffman, P. S. "Viability of Personal Rapid Transit in New Jersey", [pdf] New Jersey Department of Transportation Bureau of Research, Trenton, NJ, USA, Final report, 2007. Available at: http://faculty.washington.edu/jbs/itrans/ big/PRTfinalreport.pdf

[4] Saif, M. A., Zefreh, M. M, Torok, A. "Public Transport Accessibility: A Literature Review", Periodica Polytechnica Transportation Engineering, 47(1), pp. 36-43, 2019. https://doi.org/10.3311/PPtr.12072

[5] Eurocontrol "European Aviation in 2040, Challenges of growth, Annex 1, Flight Forecast to 2040", [pdf] European Organisation for the Safety of Air Navigation, Brussels, Belgium, 2018. advanced PRT service has the potential to mitigate many of the exacerbated problems of air travel such as the use of remote parking facilities, long walking distance, waiting in queue misplacing one's way and the continual struggle of handling heavy baggage. This service could potentially be a remedy towards achieving less airport hassle and a satisfactory traveler experience.

Designers and operators may find the elaborated method as a preliminary guide to implement an advanced PRT service at airports. The proposed system with realtime data facilitates the coordination of travel demands and services. Our further research focuses on the simulation of the advanced PRT service using real data of flight frequency, passengers travel and parking habit, and we are going to perform a cost-benefit analysis regarding the installation of the system on the proposed layout.

\section{Acknowledgment}

The research reported in this paper and carried out at the Budapest University of Technology and Economics has been supported by the National Research Development and Innovation Fund (TKP2020 Institution Excellence Subprogram, Grant No. BME-IE-MIFM) based on the charter of bolster issued by the National Research Development and Innovation Office under the auspices of the Ministry for Innovation and Technology.

[6] Bao, D., Hua, S., Gu, J. "Relevance of airport accessibility and airport competition", Journal of Air Transport Management, 55, pp. 52-60, 2016.

https://doi.org/10.1016/j.jairtraman.2016.04.009

[7] Malandri, C., Matecchini, L., Postorino, M. N. "Airport Ground Access Reliability and Resilience of Transit Networks: a Case Study", Transportation Research Procedia, 27, pp. 1129-1136, 2017. https://doi.org/10.1016/j.trpro.2017.12.022

[8] Gokasar, I., Gunay, G. "Mode choice behavior modeling of ground access to airports: A case study in Istanbul, Turkey", Journal of Air Transport Management, 59, pp. 1-7, 2017.

https://doi.org/10.1016/j.jairtraman.2016.11.003

[9] Anderson, E. W., Sullivan, M. W. "The Antecedents and Consequences of Customer Satisfaction for Firms", Marketing Science, 12(2), pp. 125-143, 1993. https://doi.org/10.1287/mksc.12.2.125

[10] Liu, X. "Assessing airport ground access by public transport in Chinese cities", Urban Studies, 57(2), pp. 267-285, 2020. https://doi.org/10.1177/0042098019828178

[11] Rothfeld, R., Straubinger, A., Paul, A., Antoniou, C. "Analysis of European airports' access and egress travel times using Google Maps", Transport Policy, 81, pp. 148-162, 2019. https://doi.org/10.1016/j.tranpol.2019.05.021 
[12] Birolini, S., Malighetti, P., Redondi, R., Deforza, P. "Access mode choice to low-cost airports: Evaluation of new direct rail services at Milan-Bergamo airport", Transport Policy, 73, pp. 113-124, 2019. https://doi.org/10.1016/j.tranpol.2018.10.008

[13] Budd, L., Ison, S., Budd, T. "Improving the environmental performance of airport surface access in the UK: The role of public transport", Research in Transportation Economics, 59, pp. 185-195, 2016.

https://doi.org/10.1016/j.retrec.2016.04.013

[14] Pasha, M. M., Hickman, M. D., Prato, C. G. "Modeling Mode Choice of Air Passengers' Ground Access to Brisbane Airport", Transportation Research Record: Journal of the Transportation Research Board, 2020. https://doi.org/10.1177/0361198120949534

[15] Humphreys, I., Ison, S. "Changing airport employee travel behaviour: the role of airport surface access strategies", Transport Policy, 12(1), pp. 1-9, 2005.

https://doi.org/10.1016/j.tranpol.2004.07.002

[16] Miyoshi, C., Mason, K. J. "The damage cost of carbon dioxide emissions produced by passengers on airport surface access: the case of Manchester Airport", Journal of Transport Geography, 28, pp. 137143, 2013.

https://doi.org/10.1016/j.jtrangeo.2012.12.003

[17] Monsalud, A., Ho, D., Rakas, J. "Greenhouse gas emissions mitigation strategies within the airport sustainability evaluation process", Sustainable Cities and Society, 14, pp. 414-424, 2015. https://doi.org/10.1016/j.scs.2014.08.003

[18] Santa, S. L. B., Ribeiro, J. M. P., Mazon, G., Schneider, J., Barcelos, R. L., de Andrade Guerra, J. B. S. O. "A Green Airport model: Proposition based on social and environmental management systems", Sustainable Cities and Society, 59, Article number: 102160, 2020. https://doi.org/10.1016/j.scs.2020.102160

[19] National Academies of Sciences, Engineering, and Medicine "Guidebook for Planning and Implementing Automated People Movers Systems at Airports", National Academy of Sciences, Washington, DC, USA, 2010.

https://doi.org/10.17226/22926

[20] Hong, S.-J., Choi, D., Chae, J. "Exploring different airport users' service quality satisfaction between service providers and air travelers", Journal of Retailing and Consumer Services, 52, Article number: 101917, 2020. https://doi.org/10.1016/j.jretconser.2019.101917

[21] Liu, S., Schonfeld, P. M. "Effects of Driverless Vehicles on Competitiveness of Bus Transit Services", Journal of Transportation Engineering, Part A: Systems, 146(4), 2020. https://doi.org/10.1061/JTEPBS.0000327

[22] National Academies of Sciences, Engineering, and Medicine "Transit Capacity and Quality of Service Manual", 3rd ed., The National Academies Press, Washington, DC, USA, 2013. https://doi.org/10.17226/24766

[23] Anderson, J. E. "A Review of the State of the Art of Personal Rapid Transit", Journal of Advanced Transportation, 34(1), pp. 3-29, 2000. https://doi.org/10.1002/atr.5670340103
[24] Irving, J. H., Bernstein, H., Olson, C. L., Buyan, J. "Fundamentals of personal rapid transit", Lexington Books, El Segundo, CA, USA, 1978.

[25] Anderson, J. E. "Safe design of personal rapid transit systems", Safety Science, 19(2-3), pp. 256-263, 1995. https://doi.org/10.1016/0925-7535(94)00027-Z

[26] Poor, G. H., Stewart, R. B. "Beyond the airport terminal: people mover technologies at Seattle-Tacoma International Airport", In: Automated People Movers IV: Enhancing Values in Major Activity Centers: Proceedings of the Fourth International Conference on Automated People Movers: Enhancing Values in Major Activity Centers, Irving, TX, USA, 1993, pp. 403-413.

[27] Muller, P. J. "Personal Rapid Transit Applications at Airports", presented at 10th International Conference on Automated People Movers, Orlando, FL, USA, May, 1-4, 2012. https://doi.org/10.1061/40766(174)41

[28] Lowson, M. "Personal Rapid Transit for Airport Applications", Transportation Research Record: Journal of the Transportation Research Board, 1930(1), pp. 99-106, 2005. https://doi.org/10.3141/1930-12

[29] Muller, P. J. "Airport Parking Shuttle Comparison: Bus vs. Personal Rapid Transit", presented at 15th International Conference on Automated People Movers and Automated Transit Systems, Toronto, ON, Canada, 2016. https://doi.org/10.1061/9780784479797.006

[30] Krausz, N., Lovas, T., Barsi, Á. "Radio Frequency Identification in Supporting Traffic Safety", Periodica Polytechnica Civil Engineering, 61(4), pp. 727-731, 2017.

https://doi.org/10.3311/PPci.10114

[31] Tettamanti, T., Varga, I., Szalay, Z. "Impacts of Autonomous Cars from a Traffic Engineering Perspective", Periodica Polytechnica Transportation Engineering, 44(4), pp. 244-250, 2016. https://doi.org/10.3311/PPtr.9464

[32] De Oña, J., de Oña, R., Eboli, L., Forciniti, C., Mazzulla, G. "Key Transit passengers' behavioural intentions: the influence of service quality and customer satisfaction", Transportmetrica A: Transport Science, 12(5), pp. 385-412, 2016. https://doi.org/10.1080/23249935.2016.1146365

[33] Kaifi, B. A., Nafei, W. A., Khanfar, N. M., Kaifi, M. M. "A MultiGenerational Workforce: Managing and Understanding Millennials", International Journal of Business and Management, 7(24), pp. 88-93, 2012.

https://doi.org/10.5539/ijbm.v7n24p88

[34] Saaty, T. L. "How to Make a Decision: The Analytic Hierarchy Process", INFORMS Journal on Applied Analytics, 24(6), pp. 19-43, 1994.

https://doi.org/10.1287/inte.24.6.19

[35] Saaty, T. L. "Transport planning with multiple criteria: The analytic hierarchy process applications and progress review", Journal of Advanced Transportation, 29(1), pp. 81-126, 1995.

https://doi.org/10.1002/atr.5670290109 